\title{
Surgical treatment and outcomes of hydatid cyst of the spleen
}

\author{
Baraket Oussama*, Moussa Makrem, Ayed Karim, Kort Brahim, Ben Moussa Mohamed, \\ Bouchoucha Samy
}

Department of Surgery, Bizerte Hospital, Bizerte, Tunisia

Email: *oubaraket@voila.fr

Received 26 November 2013; revised 30 December 2013; accepted 10 January 2014

Copyright (C) 2014 Baraket Oussama et al. This is an open access article distributed under the Creative Commons Attribution License, which permits unrestricted use, distribution, and reproduction in any medium, provided the original work is properly cited. In accordance of the Creative Commons Attribution License all Copyrights (C) 2014 are reserved for SCIRP and the owner of the intellectual property Baraket Oussama et al. All Copyright (C) 2014 are guarded by law and by SCIRP as a guardian.

\section{ABSTRACT}

Aim: Discuss the different modalities of surgical treatment of splenic hydatid cyst and outcomes after treatment. Patients and Methods: Retrospectively, 14 patients were operated in our institution between 2002 and 2011. Results: A total splenectomy was performed in 8 cases. A conservative treatment was preferred in 6 cases: 2 patients underwent partiel splenctomy and two patients underwent partial cystectomy. The duration of hospitalization ranged from 5 to 15 days. The morbidity rate was $14 \%$. One patient presented a recurrent hemorrhage and one patient developed a left pneumonia. There is no death in our series. The mean duration follow-up was $\mathbf{2 0}$ months and there is no recurrence. Conclusion: Management of a splenic hydatid cyst is not consensual. Surgery remains the treatment of choice to avoid serious complications. Total splenectomy is optimal because it provides definitive treatment. However, spleen-preserving surgery is the preferred treatment in some selected patients.

\section{KEYWORDS}

Hydatid Cyst; Spleen; Surgery; Outcomes

\section{INTRODUCTION}

Hydatid disease is a zoonotic infection caused by the larval stage of the genus Echinococcus, also known as $E$. granulosus. It remains a considerable public health problem in several Mediterranean countries [1].

Although it most frequently localized to the liver (60\% - 70\%) and lung (20\%), it can be developed in any organ system in the body. The spleen localization is the third

${ }^{*}$ Corresponding author. most organs which can be affected. Even in country where hydatid disease is endemic, the splenic localization is uncommon. It occurs in $0.5 \%$ - $6 \%$ of cases and it can either be isolated or concomitant with liver hydatid disease.

\section{MATERIAL AND METHODS}

Between January 2002 and December 2011, 14 patients who were operated in our department for a hydatid cyst of the spleen were reviewed retrospectively. In this period about 158 patients were operated for a hydatid cyst of the liver.

Epidemiologic characteristics of the patients, their symptoms, findings of the physical examinations and laboratory analyses radiographic investigations [plain chest $\mathrm{X}$-ray, abdominal ultrasonography (USG), computed tomography (CT)], other organs involved, surgical methods implemented, length of hospital stay, postoperative complications, disease relapses, and mortality characteristics were specifically recorded.

The surgical techniques used are: a total splenectomy, a partial splenectomy and a partial resection of the cyst.

Total splenectomy: Splenic artery is divided between ligatures with gastrosplenic omentum. The smaller vessels are divided between ligatures starting at one end of the hilus and proceeding to the other. The splenic vein is ligated last.

When we done a partial splenctomy upper or lower polar artery and vein, far from the cyst, were isolated and preserved. Subsequently, 1/3, 1/4 of splenic length was measured, and the remaining tissues were removed through a fish mouth incision. The partial resection of the cyst consist on resection of the wall of the cyst after aspiration of the cyst witch evacuated using a large-gauge sump drain, and the residual cavity is filled with a $15 \%$ saline solution. Ommentoplasty was used if a partial resection 
of the cyst was done. In all cases external drainage was performed.

A total splenectomy was undertaken in cases with multiple and large central and hilar located cysts, larger cysts when the splenic parenchyma is significantly reduced due to pressure atrophy and thick fibrous membrane and in cases with simultaneous involvement of other abdominal organs. In contrast, spleen-saving procedures were preferred in younger cases with small, solitary, peripherally located cysts, for superficial cysts confined to one of the poles of spleen and cysts with extensive adhesions.

Medical treatment was indicated in multiple cysts, multiple initial locations, and recurrence in multiple organs. It is usually preferred at an average daily dosage of 15 $\mathrm{mg} / \mathrm{kg} / \mathrm{day}$; it must be given continuously. Blood count and transaminases must be checked every week for the $1^{\text {st }}$ month and every month thereafter.

When a total splenectomy was indicated; because the risk of overwhelming post-splenectomy infection (OPSI), the patients receive immunization against $\mathrm{S}$. pneumoniae using the 23-valent pneumococcal polysaccharide vaccine (Pneumovax). It was given if possible 2 weeks before surgery or as soon as after splenectomy. Antibiotic prophylaxis usually single daily dose of penicillin or amoxillin was begun before surgery and continued 5 days after surgery.

\section{RÉSULTS}

Their mean age was 38.8 years (range 20 - 66 years). There were 10 male and 4 female patients. The spleen was the only location of the disease in 8 patients, one patient had operated three years later for a hydatid cyst of the liver, and in 7 cases spleen was the primary location of the cyst. In six cases (54.54\%), there is a splenic hydatid cyst with coexistent cysts in another organ (three liver, one kidney, one pelvic, and one omental cyst). Left hypochodrium pain was the mean symptom in 8 cases. Two patients were admitted for Mild abdominal discomfort, one patient with splenomegaly. In three cases the hydyatid cyst was asymptomatic and diagnosed incidentally (Table 1).

Hydatid cyst serology was positive in 9 cases, negative in 3 cases. We haven't done it in 2 cases. Indirect hemagglutination (IHA) was used in 10 cases, indirect fluorescent antibody (IFA) test was used in two cases.

Abdominal plain X-ray, abdominal Ultra-sonography (Figure 1), were implemented in all patients. CT scan was implanted in ten patients (Figures 2 and 3). The mean cyst diameter was $6.6 \mathrm{~cm}$ (range $3-13.5 \mathrm{~cm}$ ). The most common radiographic finding was splenomegaly (in 6 of 10 cases) or a soft tissue mass in the left hypochondrium. The cysts were partly calcified in eight patients and completely calcified in two. A single cyst was obser-

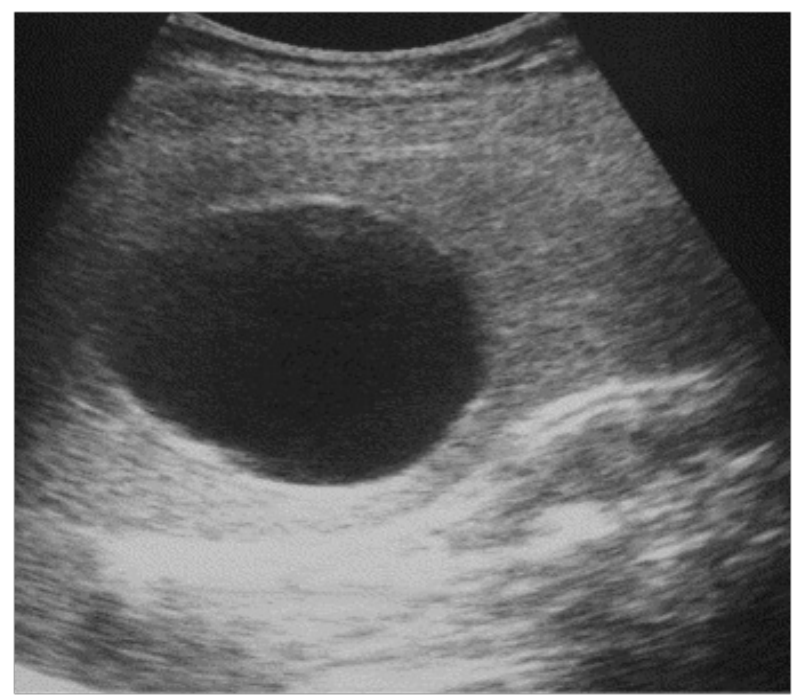

Figure 1. Abdominal ultrasonography showing hydatic cyst.

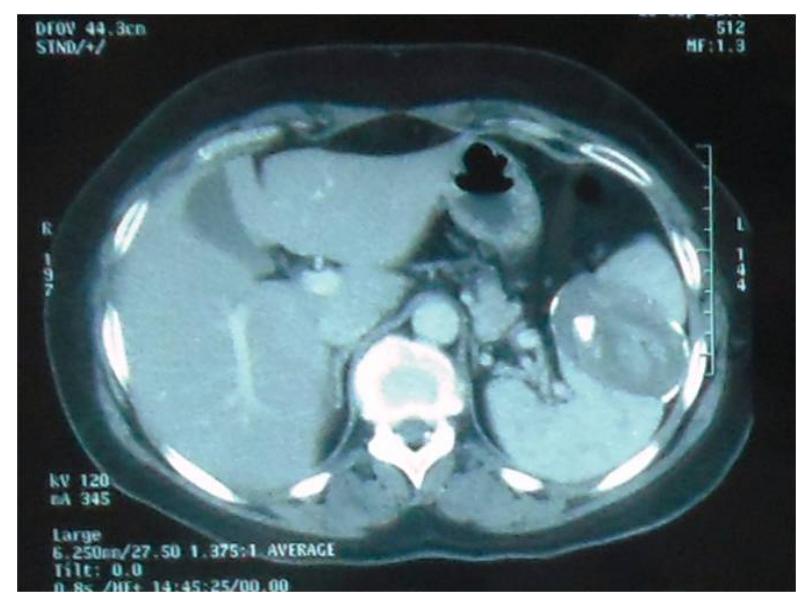

Figure 2. CT scan showing calcified hydatid cyst.

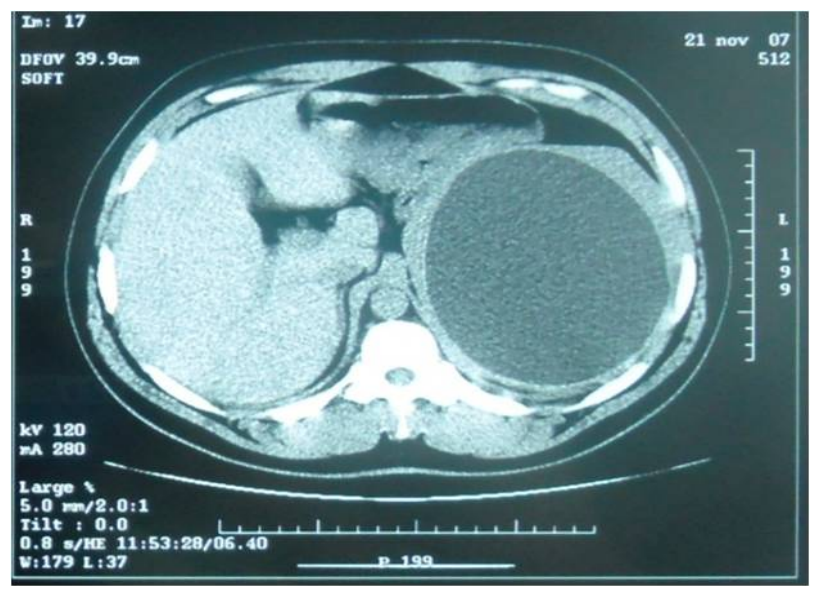

Figure 3. CT scan showing type1 hydatid cyst.

ved in 13 cases, a multiple cyst was observed in one case.

Median supraumbilical incision was used in 12 cases and a left subcostal incision in two cases. 
Table 1. characteristics of the patients in our study.

\begin{tabular}{|c|c|c|c|c|c|}
\hline & Age/Gender & Symptoms & Size of cyst & Surgery & Follow up (M) \\
\hline 1 & $42 / \mathrm{F}$ & Left H pain & $3 \mathrm{~cm}$ & P. cystectomy & 8 \\
\hline 2 & 28/M & Left H pain & $4.8 \mathrm{~cm}$ & P. splenectomy & 10 \\
\hline 4 & $66 / \mathrm{F}$ & Left H pain & $6.5 \mathrm{~cm}$ & P. cystectomy & 20 \\
\hline 5 & 26/M & Left H pain & $3.8 \mathrm{~cm}$ & P. cystectomy & 12 \\
\hline 6 & $42 / \mathrm{M}$ & Left H pain & $4.8 \mathrm{~cm}$ & P. splenectomy & 40 \\
\hline 7 & $32 / \mathrm{F}$ & A discomfort & $8 \mathrm{~cm}$ & T. splenectomy & 10 \\
\hline 8 & $40 / \mathrm{M}$ & Splenomegaly & $13 \mathrm{~cm}$ & T. splenectomy & 12 \\
\hline 9 & $30 / \mathrm{M}$ & Left H pain & $9 \mathrm{~cm}$ & T. splenectomy & 30 \\
\hline 10 & 28/M & Incidentally & $6.5 \mathrm{~cm}$ & T. splenectomy & 24 \\
\hline 11 & $58 / \mathrm{M}$ & Left H pain & 7.5 & T. splenectomy & 22 \\
\hline 12 & $31 / \mathrm{F}$ & Incidentally & $8 \mathrm{~cm}$ & T. splenectomy & 14 \\
\hline 14 & 38/M & Left H pain & $7 \mathrm{~cm}$ & T. splenectomy & 10 \\
\hline
\end{tabular}

The location of the cyst was the peripheral in seven cases, Central in three cases and perihelium part of the spleen in 5 cases.

A total splenectomy (Figure 4) was preferred as the surgical approach in eight patients, whereas a conservative management was preferred in 6 cases: two patients a partiel splenectomy. Four patients underwent a partial cystectomy associated with ommentoplasty in 2 cases.

The duration of hospitalization ranged from 5 to 15 days. The postoperative course was uneventful in twelve cases (85\%). One patient, who underwent partial spleenctomy, presented recurrent hemorrhage and he needs reintervention. Per operatively we found a hemorrhage for a spleen; a cauterization associated with a gelatin sponge stopped the bleeding. Another patient presented a left pneumomia treated by antibiotherapy in a patient who underwent total splenectomy. The morbidity rate was $16 \%$ in a conservative management group and $11 \%$ in the radical management group.

No surgical mortality was observed in our series.

Medical treatment with albendazole was indicated after intervention in four patients who have another location of hydatid cyst and in the patient who has a recurrence of hydatid cyst of the liver. The mean duration of follow-up was 17 months (range 8 - 40 months). There was no known recurrence or late complications in the patients followed regularly with physical examination and abdominal ultrasonography.

\section{DISCUSSION}

Cystic lesions of the spleen are unusual and comprise nonparasitic (pseudocysts, dermoid, epidermoid or epithelial cysts, and cystic hemangiomas or lymphangiomas) and parasitic forms. Hydatid cyst disease remains a considerable public health problem, especially in pastoral and

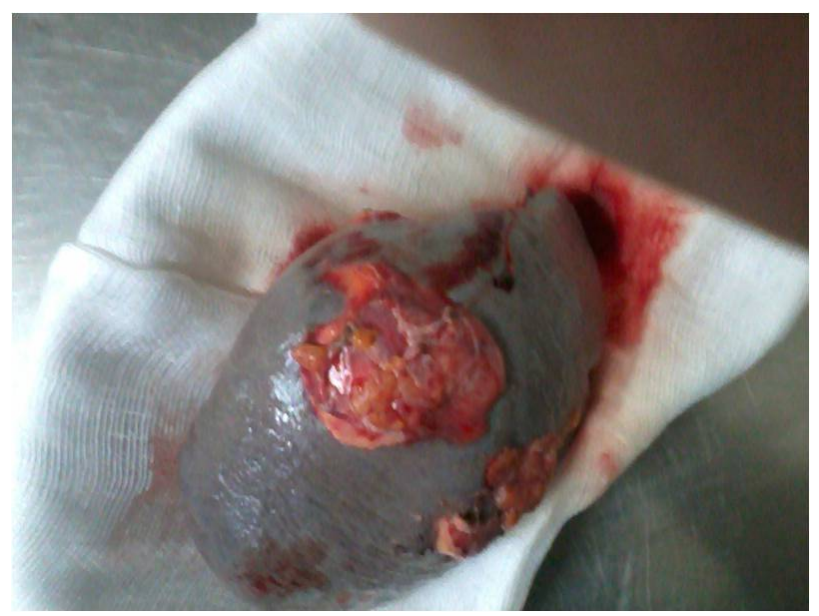

Figure 4. Per operatively view: total splenectomy for multiple hydatid cyst.

farming regions. Splenic hydatid disease is observed in $0.5 \%-4 \%$ cases of abdominal hydatidosis [1-3]. The frequency of splenic hydatid cyst in our study was compatible with that reported in the literature. The latent period of cyst development is usually long: 5 to 20 years. Splenic hydatid cysts develop insidiously and may reach a large size. Clinical manifestations of hydatid splenic disease are usually mild and no specific. In our study 70\% of our patients presented with pain of the left hypochondrium. The mean symptom in the literature is the mild abdominal discomfort [2,4]. Others symptoms are left hypochondrium pain, left hypochondrium mass. Complications such as rupture into the abdominal cavity, secondary infection or anaphylactic choc can be reported [5].

Splenic hydatid cyst can be diagnosis preoperatively and it greatly aided by the abdominal ultrasonography and CT scan. However sonographic and CT finding are not specific [2]. 
Treatment for a splenic hydatid cyst should be either conservative or surgical. Small asymptomatic cysts can be treated with anthelmintic drugs [3]. However, splenic cysts should be closely followed up. We think that medical treatment is not a sure method for a treatment for hydatid cyst of spleen and surgical treatment is the only curative treatment.

As for hepatic hydatidosis, several surgical techniques have been applied to splenic hydatid disease ranging from total splenectomy (performed in most of our patients) to more conservative procedures (partial splenectomy, cyst enucleation, or omentoplasty after partial resection of the cyst wall) [6,7].

When we choose conservative procedure; the splenic cyst is evacuated using a large-gauge sump drain, and the residual cavity is filled with a $15 \%$ saline solution. These techniques are used for superficial cysts, cysts localized in one pole of the spleen, or cysts that are unresectable due to extensive adhesions. Partial splenectomy is a hemorrhagic operation because it is difficult to have vascular control when incising the splenic tissue, whereas unroofing the cyst wall leaves behind the pericystic layer and a residual cavity, which carries the risk of postoperative infection [8,9]. Total splenectomy is the preferred approach undertaken in cases with larger, multiple, and symptomatic cysts of central or hilar location or in cases with simultaneous involvement of other organs $[6,8]$. For the above reasons and the possibility of multiple splenic cysts, we think like many authors are in favor of splenectomy for the treatment of spleen hydatid disease. Total splenectomy was uses in $60 \%$ to our patients. Partial excision with omentoplasty is reserved for cases with unresectable cysts tightly adherent to adjacent structures. Splenic salvage is also justified for pediatric cases to avoid septic complications [9-11]. In fact sepsis-related mortality rates are $4 \%$ in children and $1.9 \%$ in adults. In the case of associated hepatic involvement, splenectomy is followed by surgical management of hepatic cysts, usually omentoplasty. Many others show recurrence rate after total splenectomy do not differ significantly from spleen-preserving surgery and complication rates are also comparable. In fact Atmatzidis, et al. [12] compared splenectomy and spleen-preserving surgery. There was no significant difference between the splenectomy and spleenpreserving groups concerning median hospital stay and post-operative complication rate. The median follow-up was 52 months. Recurrence occurred in $12 \%$ patients in the splenectomy group and in $14 \%$ patients in the spleenpreserving group. The study concluded there showed no significant increase in recurrence between the two surgical approaches.

Laparoscopic [13-15] and robotic procedures [16] have also been described among surgical treatments. However, there is great reluctance to implement these procedures for fear that rupture of the cyst may lead to intraperitoneal dissemination of cystic contents, thereby inducing anaphylactic shock and recurrence. In our experience we have done laparoscopic splenectomy for other begnin tumor of the spleen but not in hydatid disease. Medical treatment is still controversial. For some authors Preoperative administration of anthelmintic drugs softens the cysts, reduces intracystic pressure facilitating their remo$\mathrm{val}$, and postoperative use reduces the rate of recurrence [16-19]. In our experience we haven't use medical treatment as exclusive for hydatid cyst of the spleen.

Despite the number of therapies now available, recurrence remains one of the major problems in the management of hydatid disease, ranging from $4.6 \%$ to $22.0 \%$ [20-23] in different series. The main reasons for recurrence appeared to be microscopic spillage of live parasites, failure to remove all viable cysts at inaccessible or difficult locations, or leaving a residual cyst wall at the initial operation. The fact that appropriate primary treatment failed owing to "vitality" of the parasite, more radical treatment might be indicated. In patients with recurrence after evacuation of cyst contents, complete cyst resection could appear to be reasonable, so long as it would be done safely. However, these radical operations are technically more difficult, and reoperations have higher morbidity and mortality rates. In most recurrent cases, conservative treatment (repeat evacuation with or without partial cystectomy) can be done [22]. Adjuvant medical treatment should be indicated in patients with recuurent hydatid cyst.

\section{CONCLUSION}

Hydatid cyst Management of a splenic hydatid cyst is not consensual. Surgery remains the treatment of choice to avoid serious complications. Total splenectomy is optimal because it provides definitive treatment. However, spleen-preserving surgery is the preferred treatment in some selected patients. The place of laparoscopic and robotic treatment is controversial. In our study, there is no recurrence in patient followed regularly.

\section{REFERENCES}

[1] Franquet, T., Montes, M., Lecumberri, F.J., Esparza, J., Bescos, J.M. (1990) Hydatid disease of the spleen: Imaging finding in nine patients.

[2] Narasimharao, K.L., Venkateswarluk, K., Mitta, S.K. and Metha, S. (1987) Hydatid disease of the spleen treated by cyst enucleation and splenic salvage. Journal of Pediatric Surgery, 22, 138. http://dx.doi.org/10.1016/S0022-3468(87)80431-1

[3] Safioleas, M., Misiakos, E. and Manti, C. (1997) Surgical treatment for splenic hydatidosis. World Journal of Surgery, 21, 374-378. http://dx.doi.org/10.1007/PL00012256 
[4] Spinelli, C., Berti, P., Gori, L., Pierallini, S. and Miaoli, P. (1992) Extrahepatic abdominal hydatidosis: Surgical features of 11 cases. Italian Journal of Gastroenterology, 24, 446-448.

[5] Rasheed, K., Zargar, S. and Telwani, A. (2013) Hydatid cyst of spleen: A diagnostic challenge. North American Journal of Medical Sciences, 5, 10-20.

[6] Arikanoglu, Z., Taskesen, F. and Gumus, H. (2012) Coll electing a surgical modality to treat a splenic hydatid cyst: Total splenectomy or spleen-saving surgery? Journal of Gastrointestinal Surgery, 16, 1189-1193. http://dx.doi.org/10.1007/s11605-012-1837-2

[7] Fernández-Ruiz, M., Guerra-Vales, J.M., Enguita-Valls, A.B., Vila-Santos, J., García-Borda, F.J. and Morales-Gutiérrez, C. (2008) Splenic hydatid cyst, a rare location of extrahepatic echinococcosis: Report of six cases. European Journal of Internal Medicine, 19, 51-53. http://dx.doi.org/10.1016/j.ejim.2008.02.003

[8] Narasimharao, K.L., Venkateswarluk, K., Mitta, S.K. and Metha, S. (1987) Hydatid disease of spleen treated by cyst enucleation and splenic salvage. Journal of Pediatric Surgery, 22, 138. http://dx.doi.org/10.1016/S0022-3468(87)80431-1

[9] Atmatzidis, K., Papaziogas, B., Mirelis, C., Pavlidis, T. and Papaziogas, T. (2003) Splenectomy versus spleen-preserving surgery for splenic echinococcosis. Digestive Surgery, 20, 527-531. http://dx.doi.org/10.1159/000073689

[10] Rodríguez-Leal, G.A., Morán-Villota, S., Milke-García and Mdel, P. (2007) Splenic hydatidosis: A rare differential diagnosis in a cystic lesion of the spleen. Revista de Gastroenterología de México, 72, 122-125.

[11] Kaya, B., Uçtum, Y. and Kutanış, R. (2010) Splenic hydatid cyst attacking retroperitoneum. Türkiye Parazitoloji Dergisi, 34, 193-195. http://dx.doi.org/10.5152/tpd.2010.12

[12] Cordoba, E., Escartin, J., Cantin, S., Artigas, J.M. and Esarte, J.M. (2001) Hydatic cyst of spleen. Journal of Clinical Gastroenterology, 33, 89-90. http://dx.doi.org/10.1097/00004836-200107000-00027

[13] Atmatzidis, K., Papaziogas, B., Mirelis, C., Pavlidis, T. and Papaziogas, T. (2003) Splenectomy versus spleen-preserving surgery for splenic echinococcosis. Digestive Surgery, 20, 527-531. http://dx.doi.org/10.1159/000073689
[14] Gharaibeh, K.I.A. (2001) Laparoscopic excision of splenic hydatid cyst. Postgraduate Medical Journal, 77, 195196. http://dx.doi.org/10.1136/pmj.77.905.195

[15] Khoury, G., Abiad, F., Geagea, T., Nabout, G. and Jabbour, A. (2000) Laparoscopic treatment of hydatid cysts of the liver and spleen. Surgical Endoscopy, 14, 243-245. http://dx.doi.org/10.1007/s004640000028

[16] Polat, F.R., Sezer, A. and Polat, S. (2009) Laparoscopic treatment of hydatid cyst of the spleen without splenectomy: Report of a case. Surgical Laparoscopy Endoscopy \& Percutaneous Techniques, 19, e215-e216. http://dx.doi.org/10.1097/SLE.0b013e3181ba474d

[17] Vasilescu, C., Tudor, S., Popa, M., Tiron, A. and Lupescu, I. (2010) Robotic partial splenectomy for hydatid cyst of the spleen. Langenbeck's Archives of Surgery, 395, 11691174. http://dx.doi.org/10.1007/s00423-010-0647-9

[18] Wani, R.A., Malik, A.A., Chowdri, N.A., Wani, K.A. and Naqash, S.H. (2005) Primary extrahepatic abdominal hydatidosis. International Journal of Surgery, 3, 125-127. http://dx.doi.org/10.1016/j.ijsu.2005.06.004

[19] Hansen, M.B. and Moller, A.C. (2004) Splenic cysts. Surgical Laparoscopy Endoscopy \& Percutaneous Techniques, 14, 316-322. http://dx.doi.org/10.1097/01.sle.0000148463.24028.0c

[20] Vezakis, A., Dellaportas, D., Polymeneas, G., Tasoulis, M.K.C. and Chondrogiannis, M.A. (2012) Two cases of primary splenic hydatid cyst in Greece. Korean Journal of Parasitology, 50, 147-150. http://dx.doi.org/10.3347/kjp.2012.50.2.147

[21] Malik, A.A., ul Bari, S., Younis, M., Wani, K.A. and Rather, A.A. (2011) Primary splenic hydatidosis. Indian Journal of Gastroenterology, 30, 175-177. http://dx.doi.org/10.1007/s12664-011-0104-x

[22] Rasheed, K., Zargar, S. and Telwani, A. (2013) A hydatid cyst of spleen: A diagnostic challenge. North American Journal of Medical Sciences, 5, 10-20.

[23] Gollackner, B., Längle, F., Auer, H., Maier, A., Mittlböck, M., Agstner, I., et al. (2000) Radical surgical therapy of abdominal cystic hydatid disease: Factors of recurrence. World Journal of Surgery, 24, 717-721. http://dx.doi.org/10.1007/s002689910115 